\title{
Children with Gilles de la Tourette syndrome at school
}

\author{
Spyridoula Laschou ${ }^{1}$, Maria Dermanopoulou ${ }^{2}$, Alexandra Marmangelou ${ }^{3}$, Maria Papaspyrou ${ }^{2}$ \\ ${ }^{1}$ Primary Education department, University of Thessaly, Volos, Greece \\ ${ }^{2}$ ICU, General Hospital Of Trikala, Trikala, Greece \\ ${ }^{3}$ Primary Education department, Florina, Greece
}

\section{Email address:}

spuridoulalaschou@gmail.com (Laschou S.), mdermanopoulou@yahoo.gr (Dermanopoulou M.), alexandramarmaggelou@hotmail.com. (Marmaggelou A.), mariapapaspiroy@gmail.com (Papaspurou M.)

\section{To cite this article:}

Spyridoula Laschou, Maria Dermanopoulou, Alexandra Marmangelou, Maria Papaspyrou. Children with Gilles de la Tourette Syndrome at School. American Journal of Nursing Science. Special Issue: Mental Health Care: Aspects, Challenges and Perspectives.

Vol. 4, No. 2-1, 2015, pp. 37-44. doi: 10.11648/j.ajns.s.2015040201.18

\begin{abstract}
Gilles de la Tourette syndrome is a neuro-developmental disorder characterized by the presence of multiple kinetic and vocal tics. Tics are sudden, rapid, repetitive, pointless, arrhythmic, stereotyped kinetic or vocal muscle twitches. It usually occurs before puberty and it is more often in boys than in girls, at a rate 4-6 / 1000. Although it doesn't affect the physical health of the patient, it creates several social problems. Most of the children who deal with Tourette syndrome have normal intelligence and brain anatomy. Purpose: this study is the early identification of children who are suffering with Tourette syndrome as a result of their clinical assessment and information of children and their families in an effort to understand the nature of this syndrome.Method:an extensive search for articles and publications in Greek and international literature was performed. Furthermore, search performed also in the electronic databases "pubmed" and "cinahl". Results: Depending on the severity of convulsive movements and if learning difficulties are present or not, the suffering student may face serious problems in school that may affect his performance. A coordinated effort by health professionals, parents and teachers who are addressing them can prevent the devastating consequences of the syndrome in childhood and later in adult life.It is helpful for the teacher to be aware of the syndrome and to encourage children that are suffering by the syndrome, to courses and protect them from being teased by their classmates. Conclusions: Parents should inform teachers about the syndrome and teachers in turn should encourage the child in his courses and protect it so in an effort to avoid isolation or aggression. Those children are usually able to attend an ordinary school unless there is a coexistence of learning disabilities or Attention-Deficit Disorder then special handling by the teacher is needed as well as tolerance, patience, and the assessment of the student should be under indulgence always in collaboration with parents and a child psychiatrist .
\end{abstract}

Keywords: Tourette Syndrome, Learning Difficulties, Special Education, School Nurse

\section{Introduction}

Gilles de la Tourette syndrome is a neurodevelopmental disorder characterized by the presence of multiple kinetic and vocal tics. Tics are sudden, rapid, repetitive, pointless, arrhythmic, stereotyped kinetic or vocal muscle twitches.[1]

Tics are distinguished into kinetic and vocal, simple and complex. Simple tics are usually short in duration and they involve one muscle group only. On the other hand,complex tics are of longer durations and include a combination of movements, which often give the impression that they have a particular purpose.

Simple kinetic tics are blinking, picking up eyebrows, shaking the head, stretching the neck, shoulder lifting, thieving lips and various grins. Complex kinetic tics are bounce, touches or small Heel taps objects or other people, pulling clothes. Simple vocals are any sound like a hawk, sucking nose, throat clearing, sigh.Finally complex vocals tics are animal sounds, voices, echolalia (immediate repetition of words that have been said by someone else), palilalia, coprolalia.

The first tics usually appear in childhood between the ages of 5-7 years old and it is observed to have greater intensity and frequency in ages between 10 and 12 years old. Tics are more controlled during adolescence and many people [2] are increasing notably of the control voluntary movements $[3,4]$.In $1 / 3$ of children, tics appear after puberty, in $1 / 3$ they are largely reduced and only $1 / 3$ of the children continue to 
have significant tics after the age of 15-18.Every child that has a tick does not mean that it has the Tourette syndrome. There are a number of problems, which may contribute to the appearance of a tic especially during the school period [5].

The occurrence of Tourette syndrome is placed before puberty and more common in boys than in girls, at the rate of 4-6 / 1000 [6].Studies have indicated that there is a higher odds ratio of the syndrome in children who have a family history of the syndrome in both of the parents and that's why it is characterized as a hereditary syndrome [7].Most children with Tourette syndrome have normal intelligence and normal brain anatomy. There is an increased excitability of the brain cortical [8] it could be also related with damage by trauma or infection of the basal ganglia [9].It is now widely accepted, in contrast to the past prevailing theories, that tics aren't psychiatric-psychological disorder but they are a strictly neurological disorder .Although, in some cases it is exacerbated by conditions such as anxiety, tics having an organic etiology and more specifically related to neurotransmitters disorders.

In many cases Tourette syndrome coexists with Attention Deficit Hyperactivity Disorder (ADHD), which is one of the most common psychiatric disorders in children and occurs in preschool and early school age $[10,11]$ Children who are dealing with attention deficit and hyperactivity experience significant functionality problems both in school and in their surroundings, due the difficulty in concentration, increased mobility and their impulsivity, which may lead to antisocial behaviors and aggression [12].Most symptoms are manifested (in the $4-12 \%$ of the children) between the ages of 6 and 12 [13].

Furthermore a basic element of this syndrome is Obsessive compulsive disorder (OCD), which may lead to many problems in school.The child manifests obsessions and feels the need to do something repeatedly (compulsions) such as washing its hands frequently, checking often if the door is locked or checking to see if there is something under his $\operatorname{desk}[14]$.

Sleeping disorder such as interrupted sleep sleepwalking, nightmares, and self-destructive behavior that includes slapping themselves, lip biting and scratching their wounds may exist. also learning disorders such as dyslexia or dysgraphia dyscalculia can be noticed.

Depending on the severity of tics and the presence of learning disorders, the patient with Tourette syndrome may face serious problems in school and his school performance can be influenced.

Diagnosis will be based on: A) Age onset before 18 and usually between 6-7 years old. B) Accelerated, repetitive, pointless, and involuntary movements that affect multiple muscle groups. C) Multiple vocal tics (grunts, barks, sighs and shouting socially inappropriate words or phrases, etc.) D) Ability to voluntary suppresses movements and sounds for several minutes. E) Variations to the intensity of the symptoms for weeks or months. F) Duration of symptoms for more than a year without tic, longer than three months free period.

\section{Propose}

Aim of this literature review was to explore certain points that will make the identification of children with Tourette syndrome at school by the observation of teachers, with help of children's family and by the clinical assessment possible. Furthermore, this review aimed to provide the information of children and their families so they could be able to fully understand the nature of Tourette syndrome. It is particularly important to inform and train the school environment about this syndrome. Thus, the present study aims to assess the effectiveness of special education programs at school and whether if a school nurse could assist in addressing children with Tourette syndrome.

Material and Method This review was mainly focused on the search for studies where Tourette's syndrome was investigated within the school environment and those which referred to the clinical picture of children who may have learning disabilities and attention deficit disorder.An online search for relative literature was conducted mainly in databases such as Pubmed, SciVerse Scopus (An elsevier publishing house) and via Google scholar search engine. In addition, special education books that are taught in Greek universities were studied. The search was conducted in both English and Greek language.

Key words that were used: Tourette syndrome, Learning difficulties, special education, school nurse.

Results An on time and accurate diagnosis is not only beneficial for the child itself but also for the family and professionals, such as educators, school nurses, social workers and psychologists, who interact with the child and the family. The immediate and early intervention at an appropriate educational context and with appropriate specialists could lead children to improve their performance (up 75\%), in their development progress, cognitive skills and in the management of their behavior[15].

An early diagnosis could help the family to understand child's difficulties and it would provide the necessary guidance for all those who involved with the child, so they and the child could have desirable outcomes and last an early diagnosis could indicate appropriate and effective methods for treatment. Moreover, an early diagnosis could lead to the reduction of family stress; provide support to the family and appropriate care both medical and educational for the child. An accurate and on time diagnosis leads to an effective treatment [16].

We can classify children with Tourette's syndrome into three main categories: children that present tics only as symptoms, children that have tics and learning difficulties and finally children that apart from the above also have attention deficit and hyperactivity disorder.

\subsection{Children with Tics}

A child who dealing with Tourette syndrome could just attend an ordinary school. As it comes to kinetic and vocal tics, a private space for expression should be provided in addition to the explanations that will be given to his 
classmates for the child's condition. The special educator should be aware about tiredness from repetitive large muscle twitches tics and the effort to suppress them. Frequent convulsions could also increase the caloric needs and so a snack between meals may be needed. Moreover the amount of work may also need to be reduced. If the isolation of the child by his classmates is perceived then the child may be lead to the school's counselor / psychologist, child's classmates should be advised too by the special educator in order for the acceptance of the child to be achieved. It is from the special educator that efforts will be made to increase the student's self-esteem by rewarding every minor achievement, encourage the student to talk about his feelings and by showing him films promoted by the Tourette Syndrome Association. Special educator should be always cautious to protect the child but also prevent mocking by the child's classmates. It is the teacher's observation that may distinguish Tourette syndrome at an early stage, especially in preschool age. Attending pre-school classes can assist children because the sooner help is given, the more positive results will be. Thus, not only is it helpful for the children but for their parents also, in that by interrupting the daily care of the child, they could have some time for themselves and for their other children. In preschool education, it is not necessary to be separated from the rest of the children. Except if, the separation is necessary due a serious behavioral disorder or some other problem. A calm child could attend a kindergarten program, which is not that difficult.Of course, willingness and understanding by the teacher is required because the child's behavior could sometimes be special. Those, which pre-school education may have to offer is the attempt to communicate and socialize with other children and the obedience behavioral rules and practices of the school program [17].

Training during the school age is necessary for all children, where some skills may be obtained, perhaps not to the same extent as the rest, and a significant educational effort is required. Their education is based on not only the concept of school knowledge acquisition but also the acquisition of social and skills. Of course, expectations and aspirations of the teacher should not be permanent because during the school year they may need to revise their perception and adjust them, since the development of those children may often be surprising, sometimes pleasant and sometimes not.

During adolescence, education will depend more on their cognitive skills, knowledge obtained in primary education, by their behavioral improvement and their ability to communicate with others.For children that have few tics and an average intelligence, nothing will be mentioned because they could continue their educational process in secondary education like any other children. Those who do not have mental retardation, have obtained enough knowledge's in elementary school and their behavior and communication is improved, their attendance in secondary education could be beneficial. In order for that to be achieved the awareness of teachers and classmates is consider to be necessary in addition to the clemency of their teachers. As regards to children who have a moderate mental ability, the continuance in a special education unit is required in order for habits and basic self-care skills to be obtained. In contrast, children with severe mental retardation, education has nothing worthwhile to offer.

\subsection{Children with Tics and Learning Difficulties}

From the beginning of schooling, success in classes is the main goal for every student. This success could determine both the ability of carrying out its tasks as well as the creation for it in a climate of acceptance and recognition mainly by its peers. The coherence in "effort - success acceptance ', which is created by the student, amplify his self-emotion, offers him emotional stability to address failures, steadily orienting to succeed and strengthen selfconfidence and friendly relations. Children with learning difficulties can show unexpected, relating to their mental status, difficulties in reading, writing, listening and speaking and mathematics, although in theory the child is obtaining the basic skills required in order to learn those objectives within the context of his overall performance in other fields. Those difficulties are permanent; they persist and afflict the child despite the helpful manipulations of his environment. More specifically, in writing, it is difficult for those children to understand the structure of various kinds of speech, they make many spelling and syntactical mistakes, they do not divide the text in sections and they don't use punctuation marks, thus their texts aren't legible. Every child with learning difficulties has its own personal pace, level and Qualitative particular problems. A student with learning difficulties who does not have an adequate social status in the classroom for the reason that he has been left behind in classes, may try to attract attention by demonstrating aggression or withdrawal. Thus, he is driven away from the rest of his class and its activities, reinforcing the vicious cycle of school failure. Negative feelings of children with learning difficulties during school years cannot be avoided, but their parents support and help in addition to that from professionals can make their lives much easier. Adjustment of children in school life, so as to look less 'threatening' while encouraging and positively reinforcing them and by engaging them in activities that strengthens students emotionally can be particularly helpful. Odds ratio of marginalization and victimization is higher in individuals with dyslexia and learning difficulties, a fact which can be destructive for their self-confidence. An approach's effectiveness is primarily depending on understanding the basic principles and the term learning difficulties is referred to the need for educational assistance [18]. Therefore, success of inclusion requires the allocation of respective competencies and responsibilities in the school in addition to the effective participation of all who is involved in the educational process, teachers-students-parents [19].Over the past decades, research has indicated that, inclusion in general schools as well as education in special schools can encounter many obstacles and positive, academic and social influences are not provided [20]. A variety of rewards systems is used 
for behavior modification such as clear and direct boosters, exchangeable reward system, removal from the booster (time out) and rewarding when a desired behavior is exhibited (for example obedience) [21].

\subsection{Children with Tics and Attention-Deficit Hyperactivity}

The child with attention deficit seem withdrawn, indifferent, apathetic and preoccupied. It has difficulty in focusing his attention on an activity, makes careless mistakes, seems like his not listening when his is spoken to, doesn't follow through on the instructions given and fails to complete a task, his attention can easily be disrupted by an external stimulation and forgets his daily activities [22].

The child with hyperactivity is constantly in motion, permanently occupied by something and its energy is what characterizes it. Moving hands and feet or moving around its place is something that occurs very often and in situations in which to remain seated is expected; talking too much [23].The child that exhibits impulsive behavior often even before questions are completed answers thoughtlessly, finds it difficult to wait for its turn and interrupts or "rammed" in others (interfering in conversations or games uninvited) [24].

The teacher - special educator, always keeping in mind that as humans we tend to do and repeat some actions that make us feel good and avoid anything that displeases us, should realize that to repeat an activity, a child with Tourette should consider the activity pleasant. The objective of behavioral therapy is to learn problem-solving strategies, for persons with Attention Deficit - Hyperactivity as well as in individuals that are socializing with it, at home (parents, siblings) or at school (classmates, teachers). Thus according to behaviorism, the child is rewarded for its behavior in order to reinforce it to exhibit the desired ones[25].

\section{Addressing Tourette Syndrome at School}

The training for behavioral management is essential for the treatment [26].There are programs using a variety of teaching methods in order to reinforce positive behaviors and modify the problematic ones. Experts claim that behavior management should be complemented by a structured skill training, in order to facilitate the conquest of linguistic, communicative, social and other behavioral skills. Effective behavioral management programs are including i)integration of children in places that "normal" children are in, such as school classes, so other children can act as role models, ii) training of all people who are in contact with the child in such a way to ensure a consistent approach to child's behavioral management and, iii) the obtained social skills to be used in all circumstances and surrounding [27]. A meeting between the teacher and the children's parents at the beginning of the school year should be arranged, in which the way that school will support the needs of the student suffering from syndrome Tourette, will be discussed. Information on the possibilities, interests and needs of the student, the student's specific symptoms could be included in such discussions. Furthermore successful strategies that are used at home or in the community that could be used at school could be also referred to. If during the school day the student receives medications, parents should discuss their possible side effects in addition to the protocol for the storage and administration of medicines should also be discussed. He must be informed how Tourette's syndrome can affect the learning process, social and emotional wellbeing.The collaboration with the parents and the student is needed in order to come in an agreement for sharing specific information about Tourette with its classmates. In order to achieve this, consultation of health care providers, such as school nurses, is necessary. A system for exchanging information of student's status between professionals must be developed in order for strategies to be planned. Moreover, opportunities for physical activities must be provided to the student so he could release body tension. A basic programming of classes must be made at the beginning of the day, because when the student is tired tics tend to worsen. Additional support should be provided in cases were the student has difficulty in writing, reading or using a computer's processor. Extra time should be given to the student to complete a task; especially if his medication could cause drowsiness or thinking retardation, in this case it is better to assign smaller tasks.

Teacher should be aware about the distinction between disobedience and uncontrollable behavior. The student must be put in a position where tics will be less noticed and annoying (not in the center and in front of the class). A neat and quiet place must be provided, so he can work in the classroom. Brightly colored decorations, interesting games and other distractions can be very stimulating for a student with Tourette syndrome. External distractions, such as buzzing of fluorescent lamps, the wheezing of air conditioners and glare, should be reduced. These kinds of stimulation could make it, for a student with syndrome Tourette, very difficult to concentrate. School professionals (psychologist, counselor, nurses) should advise parents and teachers on obedience issues, creating and maintaining a consistent behavior and a management plan for school and home. Furthermore with rational expectations, to understand that tics may be exacerbated under stress and that the punishment for tics is not appropriate. Only consequences for inappropriate behavior are suitable. A transition time between activities must be offered. Finally, if it is necessary, the student must leave the class a few minutes earlier[26-29].

\section{Address Tourette Syndrome Within The Family}

Parents of a child with Tourette syndrome have to accept it and help the child to adapt to the school-social environment in collaboration with social groups. Support to this child via education should be considered as a partnership between the family and school. In particular, after a child has been 
diagnosed with Tourette syndrome, the parent should follow these steps at school: Arrange a meeting with the school to discuss the effects that Tourette's syndrome has on the child; learn if the school has had previous experience in teaching children with Tourette syndrome. What measures the school intends to take so they could support his child. discuss the possibility the rest of the class / school to be aware about Tourette syndrome, so to reduce any misunderstanding, unwanted attention or bullying. Discuss the support that Tourette's syndrome and any related conditions such as obsessive-compulsive disorder needs. To share information on strategies that at home has proven helpful.If the child is treated with medication,explain the possible side effects and inform the school about any changes on medication. Always keep in touch with the school, meet the child's teacher on a regular basis, and should keep records of discussions on the progress of the child. Discuss the ways to manage the child's tics during the school day [30].

\section{Nursing Care and Treatment}

Most of the children display repetitive movements which usually disappear over time if little attention is paid to them. The school nurse or the teacher should be asked to report the appearance of a tic which persists in a child aged 5-15 years old. If this happens, parents should be put on alert to refer the child for evaluation by a physician with expertize in tic disorders. The basis of all care is the understanding of the disease and its manifestations. Communication with the child is also important in order to help the child understand more about the problem and that he can't always control its behavior.

There is not a unique personality, for a health professional, such as a school nurse, to adopt. Different people, each with a distinct personality, can be and actually become effective. Many scientists have tried to map the desirable or necessary characteristics of the effective health care professional and specifically when he is properly trained to perform counseling. More detailed, we can say that the characteristics and skills of an effective specialist include [31]:

Caring for people. A basic characteristic of a good school nurse is showing his interest in the difficulties that are people facing. In addition, appreciation and confidence for those are seeking his help. He must have deep and sincere capacity to care for others and help parents to cope with the idea that their child has Tourette syndrome.

Acceptance and trust. Acceptance requires respect. Respect is shown by words, gestures and the body language which conveys the message "I accept you". The feeling of trust is something that the school nurse should not only feel but also show, so as the other person (the parent) feels free to express his opinion without fear. Trust or lack of it is one of the most crucial parts of a relationship. Building a TrustBased Relationship requires the clients' belief in the validity of the professional they work in partnership.

Understanding. Parents of children with special needs usually need understanding and compassion, instead of sorrow and pity. If the practitioner listens with true interest, the client then will probably select the appropriate interventions, he will show the right appreciation and warmth, and he will be specific, direct and genuine.

Response. Response begins and is maintained by displaying genuine interest and acceptance of the client. A forced smile, which is immediately recognized by most people, proves the insincerity of the professional and lack of true warmth.

Authenticity. Carl Rogers said that when you are yourself, you becoming more effective in a business relationship. What does true authenticity mean? It simply means that the professional is himself in a professional-parents relationship, with a genuine interest for the benefit of the clients. The professional is required to put aside anything that could create obstacles in building relationships with the client [32].

Attention- listening. Paying attention is a basic and fundamental skill in collaboration. Whit's includes the awareness of verbal and nonverbal messages conveyed from the parent to the professional. Genuine listening requires effort from the specialist $[33,34]$.

Ethical behavior.One of the major responsibilities of specialists who help parents is the respect of the Code of Ethics as, often, the personal information provided are confidential. If trust is broken from the professional, even once, it is hard to be regained.

Understanding of human behavior. The school nurse needs to have a basic and comprehensive knowledge of human behavior in order to help those who need their help avoid painful mistakes, which may lead to the loss of their ability to become self-sufficient and struggle for self-fulfillment.

By having all the above characteristics, a school nurse can be effective in treating a child with Tourette syndrome.

\section{Treatment}

The treatment of Tourette syndrome focuses on identifying and helping the patient manage the symptoms which are causing the most trouble or impairment $[35,36]$. Most of the cases of Tourette Syndrome are mild and don't require medical treatment [37]. Instead, behavioral psychotherapy, psycho education and personal empowerment may be sufficient. Treatments, where necessary, can be divided into those targeting tics and those targeting comorbid medical conditions that, when they occur, are often a greater cause of impairment than the tics themselves [38]. Not all people with tics have comorbid conditions[39], but when those conditions are present, they often take treatment priority. There is no cure for Tourette syndrome and no treatment that works universally for all individuals without significant adverse effects. Knowledge, education and understanding are key elements of tic disorders management $[35,36]$.

Scientific research has shown that there are two types of treatment that can effectively address tics: a) exposure and response prevention and $b$ ) habit reversal. Both methods are described below.

Exposure and response prevention is called "holding back 
tics" while habit reversal is referred to as " the use of an incompatible response" . Exposure and response prevention consists of twelve sessions and is often applied if the child has many different tics, while habit reversal consists of ten sessions and is often used if the child has a few different tics. If only one or 2-3 tics exist, the treatment may be even shorter than ten sessions. If there are many tics involved, it is more possible that there will be a reduction in the severity and number of tics, than that they will totally disappear. If the selected method is not helpful enough, the therapist may suggest trying another method in consultation with the parent The child will be assigned to do exercises at home. Depending on the age and level of independence of the child, the parent will be involved in these exercises. The daily record of the child's tics during a period of fifteen minutes will also be asked, in order to determine the efficacy of the treatment. After completion of treatment methods, there may still be tics in particular situations. The first step is the parents' study of the situations in which the child still expresses a lot of tics. Then, the therapist will find possible solutions for these situations. Sometimes this will include relaxation exercises for the child or maybe the child needs extra help to do its homework. There is no complete cure for tic disorders and even after treatment it is possible that tics will return or get worse. For this reason, a relapse prevention plan will be made before the end of the treatment. This plan describes what the child can do in order to prevent the reappearance or the worsening of the tics after the treatment has ended. The relapse prevention plan also defines what the child can do if tics come back or worsen in any case. The treatment of tics and Tourette's syndrome is multifactorial. The first step, which is sufficient in cases of simple Transient tic disorder, is the awareness of the parents, the child itself and other people (teachers, friends, etc) about the nature of the disorder, its good prognosis and its treatment. This is achieved through discussion with experts (pediatricians, pediatric neurologist, etc.) and through the internet [40]. While tics are not physically harmful for the patient, they cause difficulty in his social life [41]. As a general principle, parents should avoid yelling at or berating their children with tics or make comments. Because children with tics visit physicians when their tics are most severe, and because of the mild and waning nature of tics, it is recommended that medication not to be started immediately or changed very often. Frequently, the tics subside with awareness, reassurance, understanding of the condition and a supportive environment. When medication is used, the goal is not the complete elimination of the symptoms. More specifically the medication should be used at the lowest possible effective dose without side effects, as these may be more severe than the symptoms for which they were prescribed [42].

In cases where tics persist, the psychological support to the child and the parents counseling with experts in child psychology is of particular importance. Psychological support aims to enhance the child's self-esteem and find ways of managing stress. Relaxation techniques such as exercise, yoga or meditation, may be helpful in relieving stress which may aggravate tics, but the majority of behavioral interventions (such as relaxation training and biofeedback) haven't been systematically evaluated, they aren't in the treatments for Tourette's syndrome that have been supported empirically [43].Behavioral intervention type assistance, children learn to replace tics by more socially acceptable behaviors and are rewarded when they achieve them. Furthermore opportunities are given to them so to have "breaks" (time-outs) when they are permitted to exhibit tics. The majority of children can be controlled without requiring medication by the methods mentioned. Nevertheless, in some cases, tics which persist and as a result child's functioning could be affected. In such cases it is possible to include pharmaceutical treatment to suppress tics. Front line medications are considered those such as clonidine and clonazepam and if those fail to suppress their tics, antipsychotics such as risperidone can be used in the second phase.

Management of the symptoms of Tourette's syndrome may include medication therapies, treatments for Behavioral Disorders as well as psychological therapies. While pharmacological intervention is implemented only for the most severe symptoms, other types of treatments (such as supportive Psychotherapy or Cognitive Behavioral Therapy ) may help avoid or alleviate depression and social isolation and improve family support. Educating the patient, the family, and the community surrounding the patient (such as friends, school and church) is the key to the treatment strategy, and that might be all that is required in mild cases [44]. Instead, behavioral psychotherapy, psycho education, and personal empowerment may be sufficient [45]. Cognitive behavioral psychotherapy is useful when diagnosed with comorbid OCD [46] and there is increasing evidence supporting in particular the use of habit reversal in the treatment of tics [47].

\section{Conclusions}

The special educator is the most responsible person to handle behavioral and intelligence disorders. He intervenes and helps the child, methodically and discreetly to enhance his behavior and to cultivate his capabilities in order to achieve a smooth community integration. Also, he participates in diagnosing and intervenes for the improvement and the normalization in the child's behavior. Of course, the psychologist and the psychiatrist are responsible for those also, but the special educator is the one who will provide intervention and treatment for the improvement in the child's behavior in order to achieve good social adjustment [17]. Special education, a special school or special educators are required when comorbidity is present [48]. Taking into account the bibliography of countries with history of school nursing, it seems that the school nurse may contribute significantly to the school population health promotion holding a central role among other professionals [49]. Children with Tourette's syndrome should have unlimited support from their school because physical and mental fatigue can worsen tics. Schoolmates should be aware of this syndrome so that they can understand their classmate 
and help when required. Furthermore, the state must have special educators in order to ensure dignity in these children's care.

\section{References}

[1] Ygor Ferrão, M.D. M.Sc., James F. Leckman, M.D., Et All Tic Disorders: Some Key Issues For Dsm-V John T. Walkup, M.D., Depression And Anxiety. 2010;27:600-610

[2] Leckman, J.F., Tourette's Syndrome. Lancet.2002; 360:15771586

[3] Mueller, S.C., Jackson, G.M., Et All, Enhanced Cognitive Control In Young People With Tourette's Syndrome. Curr. Biol.2006;16:570-573.

[4] Jung, J., Jackson, S.R., Nam, K., Hollis, C., And Jackson, G.M. Enhanced Saccadic Control In Young People With Tourette Syndrome Despite Slowed Pro-Saccades. J. Neuropsychol. 2014.

[5] Scharf J.M., Miller, L.L., Mathews, C.A., Ben-Shlomo, Y. Prevalence Of Tourette Syndrome And Chronic Tics In The Population-Based Avon Longitudinal Study Of Parents And Children Cohort. J Am Acad Child Adolesc Psychiatry.2012;51(2):192-201

[6] Robertson Mm, Stern Js Tic Disorders: New Developments In Tourette Syndrome And Related Disorders. Curr Opin Neurol. 1998;11:373-380

[7] The Tourette Syndrome Association International Consortium For Genetics. A Complete Genome Screen In Sib Pairs Affected By Gilles De La Tourette Syndrome. Am. J. Hum. Genet.1999; 65:1428-1436

[8] Amelia Draper,1 Mary C. Stephenson, ., Et All., Increased Gaba Contributes To Enhanced Control Over Motor Excitability In Tourette Syndrome. Current Biology.2014; 24, 2343-2347

[9] Mejia Ni, Jankovic J.,"Secondary Tic And Tourettism". Rev Bras Psiquiatr. 2005;27(1):11-17

[10] Scahill, M. Schwab-Stone., Epidemiology Of Adhd In SchoolAge Children. Child Adolesc Psychiatr Clin N Am. 2000; 9 : $541-555$

[11] G. Polanczyk, M.S. De Lima, B.L. Horta, J. Biederman, L.A. Rohde., The Worldwide Prevalence Of Adhd: A Systematic Review And Metaregression Analysis., Am J Psychiatry. 2007;164: 942-948

[12] Feiz,Pa, Emamipour,S., A Survey On Prevalence Rate Of Attention-Deficit Hyperactivity Disorder Among Elementary School Students (6-7 Years Old) In Tehran) Procedia - Social And Behavioral Sciences.2013;84:1732 - 1735

[13] Brown Rt, Et All, Prevalence And Assessment Of AttentionDeficit/Hyperactivity Disorder In Primary Care Settings. Pediatrics.2001;107(3):1-11

[14] David E. Comings Et All, A Controlled Study Of Tourette Syndrome. I. Attention-Deficit Disorder, Learning Disorders, And School Problems Department Of Medical Genetics, City Of Hope National Medical Center, And Tprivate Practice, Duarte, Ca. 1987. Am. J. Hum. Genet; 41:701-741
[15] Gkonela E. Autisms. Oddyseas Pub.2006 Athens

[16] Peeters, T. Autism. From Theoretical Understanding To Educational Interventions. Trans.Kalomoiris G. Hellenic Company For The Protection Of People With Autism. 2000 Athens

[17] Stamatis,., Fortified Silence, Bridges Communications With The Autistic Child, Picture- Treatment - Rehabilitation. Glaros. 1987 Athens

[18] Pantelidou S. Learning Difficulties And Educational Act What And Why. Pedio Pub. 2011 Athens.

[19] Soulis G., Pedagogical Integration. From "School Segregation" In A "School For All" Typothito, 2002 Athens,.

[20] Linday, G., Educational Psychology And The Effectiveness Of Inclusion/Mainstreaming, British Journal Of Educational Psychology. 2007; 77:1-29.

[21] Dendaki A. Learning Difficulties Addh. 2009 Athens.

[22] Jennifer Creek., Lesley Lougher., Occupational Therapy And Mental Health Mprint. 2008 Churchill Livingstone.

[23] Kewley, G. Diagnosing Adhd In Children Depends On A Set Of Strict Criteria. 2011

[24] Stanley Paul David P. Orchanian Pocket., Guide To Assessment In Occupational Therapy, Thomson, Delmar Learning. 2003 America

[25] Atkinson. S., Introduction To Hilgard. Psychology. Papazisis 2003 Athens.

[26] Jordan, R. \& Powell, S. Understanding And Teaching Children With Autism. Mtf. Kaliva E. Greek Society For The Protection Of Autistic Persons. 2000. Athens

[27] Htmhttp://Www.Encephalos.Gr/Full/44-2-06g.Htm

[28] Kourkouta L, Rarra A, Fradelos E., Stigma and Children with Schizophrenia in School, Journal of Pharmacy and Pharmacology.2014 ;2:152-156.

[29] Kourkouta L, Papathanasiou I, Rarra A, Kleisiaris Ch. The Impacts of Childhood Epilepsy in School Children. Journal of Scientific Research and Reports. 2014; 3(13):1798-1804.

[30] Am J Hum Genet. 1987. 41(5): 701-741.

[31] Malikiosi- Loizou., Counseling Psychology., Hellinic Letters, 1998. Athens

[32] Kvalsund R, Growth As Self-Actualization: A Critical Approach To The Organismic Metaphor In Carl Rogers' Counseling Theory. 2003

[33] Fradelos E, Staikos Ch, The contribution of active listening in developing therapeutic relationship in mental Health practice. Scientific Chronicles.2013;18(4)213-219

[34] Kourkouta L, Papathanasiou IV. Communication in Nursing Practice . Mater Sociomed. 2014; 26(1): 65-67.

[35] Singer H.S., "Tourette Syndrome And Other Tic Disorders". Handb Clin Neurol., 2011; 100:641-57

[36] Also See Singer Hs., "Tourette's Syndrome: From Behaviour To Biology". Lancet Neurol. 2005;4(3):149-59 
[37] Tourette Syndrome: Frequently Asked Questions. Tourette Syndrome Association. Retrieved On December 29, 2011.

[38] Scahill L, Erenberg G, Et All. Tourette Syndrome Association Medical Advisory Board: Practice Committee. "Contemporary Assessment And Pharmacotherapy Of Tourette Syndrome" . Neurorx. 2006;3 (2):192-206

[39] Denckla M.B. "Attention Deficit Hyperactivity Disorder: The Childhood Co-Morbidity That Most Influences The Disability Burden In Tourette Syndrome". Adv Neurol. 2006;99:17-21

[40] Http://Www.Tourettes-Action.Org.Uk/

[41] Postgraduate Medicine Journal. 2005; 81(951):12-19

[42] Zinner S.H. "Tourette Disorder". Pediatr Rev. 2000;21(11):372-83

[43] Woods Dw, Himle Mb, Conelea Ca. "Behavior Therapy: Other Interventions For Tic Disorders". Adv Neurol. 2006;99:234-40
[44] Stern, J.S, Burza, S, Robertson, M.M., "Gilles De La Tourette's Syndrome And Its Impact In The Uk

[45] "Tourette Syndrome, Associated Conditions And The Complexities Of Treatment" Brain. 2000. 123 Pt 3:425-62. Retrieved On January 25, 2000

[46] Coffey, B.J., Shechter, R.L., "Treatment Of Co-Morbid Obsessive Compulsive Disorder, Mood, And Anxiety Disorders". Adv Neurol. 2006; 99:208-21

[47] Himle, M.B., Woods, D.W., Piacentini, J.C., Walku, J.T., "Brief Review Of Habit Reversal Training For Tourette Syndrome". J Child Neurol. 2006 ; 21(8):719-25

[48] Freeman, R.D., Tourette Syndrome International Database Consortium. Tic Disorders and Adhd: Answers from A World-Wide Clinical Dataset On Tourette Syndrome. Eur Child Adolesc Psychiatry. 2007 ; 16 Suppl 1:15-23

[49] Alexandropoulou Et All, School Health Services In Greece The Position Of School Nurse. Nursing 2006;45 (3): 308-314 